\title{
A Formação do Profissional em Saúde Coletiva: Dilemas e Desafios
}

\section{Laura Camargo Macruz Feuerwerker*}

Ao iniciar a preparação desta apresentação fui à procura de dados específicos sobre a Residência Médica na área de Medicina Preventiva e Social. Conjecturei até mesmo sobre a conveniência ou correção de agregar dados a respeito dos programas de Medicina Geral e Comunitária (seriam esses programas de formação de profissionais de saúde coletiva?).

Considero esta preocupação extremamente ilustrativa, bastante representativa até, da situação atual da formação dos profissionais de Saúde Coletiva.

Nos últimos 15 anos pelo menos, durante o processo que levou à criação do movimento pela Reforma Sanitária e mais recentemente durante o esforço pela implantação do Sistema Único de Saúde, um conjunto de idéias e propostas acerca do que deveria ser a formação e a atividade prática dos profissionais de Saúde Coletiva foi sendo elaborado.

Por outro lado, o Sistema Único de Saúde, apesar de todos os problemas, vem sendo progressivamente implantado nos municípios de todo o país. $\mathrm{O}$ número de empregos públicos na área da saúde cresceu mais do que no setor privado e atualmente os municípios já são um importante, senão o principal empregador .

Mas quem são os profissionais que trabalham nesse sistema? Quem são os profissionais que estão, na prática, sendo responsáveis pela implantação do SUS?

Dentro das escolas médicas de um modo geral a Saúde Coletiva é preocupação específica dos Departamentos de Medicina Preventiva e Social e, algumas vezes, dos Departamentos de Pediatria. E essa característica se mantém ou até se agrava ao nível da Residência Médica.

No projeto de avaliação das instituições do Programa de Bolsas administrado pela FUNDAP, realizado em 1993, foi possível verificar que a grande maio-

\footnotetext{
* Médica, pós-graduanda na Faculdade de Saúde Pública na área de formação de recursos humanos; consultora da FUNDAP na área de Residência Médica.
} 
ria dos programas de Residência nas diferantes especialidades são centrados quase exclusivamente nos hospitais. Foi também possível verificar que a maior parte dos hospitais de ensino não funciona integradamente com o restante do sistema de saúde.

Como atualmente a Residência Médica tornou-se um passo quase indispensável dentro do processo de formação dos médicos, essas características marcam profundamente o perfil dos profissionais que estão sendo colocados no mercado de trabalho e que são absorvidos pela rede pública de saúde .

Veremos mais adiante que, contrariando o processo de expansão dos Programas de Residência Médica em geral, a Residência em Medicina Preventiva e Social e em Medicina Geral e Comunitária estão definhando.

$\mathrm{Na}$ prática, na área médica, a formação dos profissionais para Saúde Coletiva ficou restrita a esses programas. Ou seja, ao nível da graduação e da Residência Médica o objeto da Saúde Coletiva ficou aprisionado; as idéias e propostas da Reforma Sanitária raramente conseguiram ultrapassar os muros dos Departamentos de Medicina Preventiva e atingir ou influenciar a formação médica em geral.

Acredito ter sido esse um erro grave de estratégia, que colaborou decisivamente para o comprometimento de um dos aspectos importantes para a viabilização do SUS: a formação de profissionais adequados à proposta. E, em minha opinião, para buscar corrigi-lo será necessário procurar ampliar a intervenção da Saúde Coletiva no ensino de graduação, ultrapassando o limite das disciplinas, e será preciso intervir também na Residência Médica.

Por outro lado, não se pode imaginar que para ampliar a influência da Saúde Coletiva sobre a formação dos médicos, para alterar o perfil dos profissionais formados ou de sua prática seja suficiente a iniciativa de levar o aprendizado prático de estudantes e residentes para outros campos de treinamento como hospitais gerais, ambulatórios, Unidades Básicas de Saúde, etc.

É preciso mais, é preciso interferir na definição do tipo de profissional que deve ser formado pelas escolas médicas. Para isso, em minha opinião, será necessário rever alguns conceitos já cristalizados na área de Saúde Coletiva a respeito do médico e de sua formação.

O movimento da Reforma Sanitária procurou realizar um profundo questionamento acerca do modelo assistencial vigente no país. Propôs-se um novo modo de abordar o processo saúde-doença inserido em sua causalidade social.

Embora não muito clara ou precisamente definido o perfil do médico que seria desejável para integrar esse tipo de modelo de atenção, esperava-se que ele fosse um profissional capacitado a integrar uma equipe multiprofissional, a participar de atividades de prevenção e promoção à saúde, além de dedicar-se às atividades assistenciais propriamente ditas.

Criticava-se, nesse processo, alguns aspectos da formação do médico: 
a) a orientação especializante, com ênfase na atividade hospitalar e com alta incorporação tecnológica;

b) o fato de a formação do médico ser voltada para a doença;

c) o fato de a formação do médico ser voltada à atenção individual.

Todo esse questionamento, entretanto, foi feito de modo insuficiente para atingir definições satisfatórias acerca do perfil e das características desejáveis do médico nesta sociedade concreta.

A primeira das referidas críticas muitas vezes levou à insatisfatória polarização "liberal-especialista-consumidor de tecnologia" $\mathrm{X}$ "assalariadogeneralista-atenção realizada com baixo emprego de tecnologia". Insatisfatória porque reduz a definição do médico necessário a uma caricatura. Insatisfatória porque não leva em conta a transformação do perfil epidemiológico das populações de países como o nosso, que sofreram intenso processo de urbanização, transformando as necessidades de saúde. Insatisfatória também por não levar adequadamente em conta a realidade econômica e cultural criada a partir da existência do complexo médicoindustrial, bastante forte, em nosso país.

A tentativa de incorporar ao trabalho médico a formação para a saúde (que costumava ser identificada com a atividade de prevenção), por outro lado, muitas vezes levou à desqualificação da prática clínica, por ela ser centrada na abordagem ao paciente através da doença. Como atualmente as bases do conhecimento e dos métodos de trabalho do médico repousam sobre o raciocínio clínico, que tem a doença como objeto, esse tipo de questionamento pode envolver precisamente a necessidade de reformulação das bases conceituais e fillosóficas da prática médica . E essa possibilidade constitui-se num grande desafio e certamente numa discussão que não foi ainda suficientemente desenvolvida.

Também a crítica ao atendimento individual levou frequentemente à desqualificação da prática clínica. Por mais que as condições de vida e a inserção do indivíduo na sociedade sejam fundamentais na determinação do processo saúde-doença, quando o indivíduo adoece, sua dor e seu sofrimento são de ordem privada. Ver a doença como fenômeno social possibilita ações sobre o coletivo, mas atender a um doente também exige ações individuais. Como abordar o doente, como definir o papel dessas ações, como combiná-las e como definir o papel do médico no domínio do combate social à doença não são tampouco questões esgotadas.

Considerar essas indefinições e a necessidade de enfrentá-las é indispensável para uma discussão adequada sobre o perfil do médico que se deseja formar e dos elementos necessários à sua formação. Essa postura pode contribuir para diminuir o fosso que atualmente separa os profissionais da Saúde Coletiva do restante dos profissionais médicos nesse debate.

Um exemplo bastante concreto da indefinição que existe até mesmo sobre quais são os conteúdos essenciais da própria Medicina Preventiva e Social na 
formação dos médicos é o resultado de um estudo acerca do processo seletivo para Residência Médica no Estado de São Paulo em 1994.

Foram submetidas a análise as provas aplicadas nos seguintes concursos:

a) FMUSP

b) Hospital das Clínicas de Ribeirão Preto

c) FM UNICAMP

d) FM Botucatu- UNESP

e) Hospital do Servidor Público Estadual

f) SUS

A 1a. fase de todos esses concursos consiste em prova de testes de múltipla escolha. As justificativas para sua adoção são: objetividade, rapidez e isenção na correção.

Os testes foram analisados estatisticamente quanto à sua distribuição pelas grandes áreas, ao grau de dificuldade das questões, ao seu poder discriminatório e, qualitativamente, em relação ao seu conteúdo.

Somente 2 concursos incluem questões sobre especialidades nos testes da 1a. fase: o da UNICAMP (com 100 questões eliminatórias sobre as áreas básicas e 50 questões de especialidades utilizadas apenas para a classificação dos candidatos) e o de Botucatu (com 60 questões sobre as áreas básicas e 40 de especialidade).

Não houve diferença estatística entre essas 6 provas em relação ao grau de dificuldade das questões (combinação de questões muito fáceis, fáceis, médias, difíceis e muito difíceis). Também não houve diferença estatística em relação poder discriminatório das questões.

A análise qualitativa das questões revelou dois elementos de diferenciação:

a) apesar de todas as provas conterem questões teórico-conceituais, operacionais e estudos de caso, existe uma variação significativa em relação ao seu predomínio dentre as diferentes áreas (Clínica, G-O, Pediatria e Cirurgia) de uma mesma prova e entre os vários concursos, muito embora os temas abordados fossem semelhantes;

b) na área de Saúde Pública/Coletiva/Medicina Preventiva, os testes revelaram grande disparidade em relação aos conteúdos abordados: vigilância epidemiológica, método epidemiológico, políticas de saúde, saúde do trabalhador, etc.

O primeiro elemento provavelmente manifesta a "personalidade" das escolas, aspectos filosóficos e diferentes concepções sobre educação médica. Apesar disso, existe similaridade em relação aos assuntos e temas abordados.

No segundo caso, a diversidade provavelmente reflete as diferentes orientações dos Departamentos de Medicina Preventiva e Social das escolas médicas e ilustra a indefinição a que nos referíamos.

Aparentemente, portanto, não existe um posicionamento claro acerca de qual deva ser o conteúdo transmitido pela Medicina Preventiva durante a gra- 
duação, qual deva ser a marca impressa pela Saúde Coletiva na formação do aluno de graduação.

Um outro aspecto do referido estudo foi a análise do desempenho obtido na 1a. fase do processo seletivo de todos os concursos de Residência Médica do Estado de São Paulo. Foram convidados a integrar o universo desta fase da pesquisa todas as instituições que são responsáveis por programas credenciados pela Comissão Nacional de Residência Médica em São Paulo: são 546 programas que oferecem 2131 vagas. Foram obtidos os dados referentes a $92,49 \%$ dos programas e $93,95 \%$ das vagas.

Inscreveram-se nesses concursos 4945 médicos: 2157 mulheres $(43,6 \%)$ e 2788 homens $(56,4 \%)$. Compareceram às provas 4243 candidatos, perfazendo a relação de 2,38 candidatos por vaga, em média.

Cada candidato realizou, em média, 4,95 inscrições, atingindo-se um total de 24486 inscrições.

A grande maioria dos candidatos eram médicos formados em 1993. Os formados em anos anteriores representam $27,64 \%$ dos candidatos.

Em 1993 formaram-se 1541 médicos em escolas paulistas e $5365 \mathrm{em}$ outros Estados. Inscreveram-se nos exames de São Paulo 95,78\% dos formados em São Paulo e 35,73\% dos formados nos demais Estados. Ou seja, 49,13\% dos médicos formados em 1993 no Brasil.

As chamadas especialidades básicas (Clínica Médica, Obstetrícia e Ginecologia, Pediatria e Cirurgia Geral) concentraram 17585 inscrições ( $71,8 \%$ do total) para 1146 vagas $(64,2 \%$ do total).

Outras especialidades com número significativo de inscrições foram Oftalmologia (1518), Radiologia (1231) e Anestesiologia (1058).

Houve 34 inscrições para Medicina Preventiva e Social (para 40 vagas) e 17 inscrições para Medicina Geral e Comunitária (para 10 vagas).

A diminuição de procura pela Residência em Medicina Preventiva e Social e em Medicina Geral e Comunitária é um fenômeno nacional, mas é muito mais intenso no Estado de São Paulo.

Segundo dados da Comissão Nacional de Residência Médica, em 1985 havia 80 residentes de Preventiva em São Paulo. Esse número chegou a subir a 102 em 1987, mas caiu para 46 desde 1991, uma redução de mais de 50\% se se considera o pico atingido em 87 .

No Brasil como um todo, em 85 havia 197 residentes, em 87, 239 e, a partir de 1991, são 180 os residentes da área anualmente. A redução foi de $25 \%$.

Em 1993, houve 13 candidatos de outros Estados e 29 de São Paulo nos concursos para Medicina Preventiva em São Paulo. Em 1994 foram 16 candidatos de outros Estados e 18 de São Paulo.

Em 1993 dos 21 residentes de 1o. ano, 15 eram de São Paulo. Em 1994, dos 10 residentes, somente 3 eram de São Paulo. 
Quando se considera o total de candidatos dos concursos, os de São Paulo correspondem a $40 \%$ do total, mas, na composição final dos residentes a participação dos paulistas sobe para $63,4 \%$.

Dos 593 candidatos de São Paulo formados em faculdades públicas, 404 tornaram-se residentes, 69 foram aprovados em algum concurso mas foram convocados para o Serviço Militar. Não se tornaram residentes 104 (17,5\%) .

Dos 1384 candidatos de São Paulo formados em escolas privadas, 589 tornaram-se residentes, 75 aprovados foram para o Serviço Militar e 736 (53\%) não se tornaram residentes.

Considerando-se que a grande maioria dos médicos que se formam em São Paulo procuram a Residência Médica, entender exatamente o papel que ela cumpre na formação dos médicos e quais as repercussões desse fenômeno para a viabilização do SUS e para a Saúde Coletiva é fundamental.

Como já foi dito, existe um movimento inverso na área de Preventiva em relação ao que ocorre na busca da Residência Médica em geral. Esse fenômeno é mais intenso em São Paulo. Seria importante entender esse processo e seu significado.

É preciso também encarar de frente o problema da qualidade dos cursos e a responsabilidade das escolas na educação continuada dos médicos no processo de definição de uma proposta adequada de formação médica.

Considero serem essas questões essenciais para todos os movimentos e instituições interessadas em intervir no necessário processo de transformação da formação médica e na indispensável redefinição do processo de formação de profissionais de Saúde Coletiva. 